\title{
Same Words, Different Worlds: Exploring Differences in Researcher and Participant Understandings of Promise and Obligation in the Psychological Contract
}

Word count: 6, 356 (excluding references)

\begin{abstract}
This paper addresses longstanding questions about how promise and obligation, two of the key conceptual building blocks for psychological contract research, are conceptualized and operationalized (see Conway \& Briner, 2005; Rousseau, 2011; Bankins, 2014): How do employees understand these concepts? Would their understandings be congruent with the researchers' and how would this knowledge inform future psychological contract research? Drawing on interviews with 61 Chinese workers from diverse backgrounds, our results suggest the concepts have distinct meanings for participants in terms of three criteria (defining characteristics, key features, and manifestations in employment). We argue that promise and obligation are likely to serve different functions in employment relationship, and have different meanings for researchers versus participants, and accordingly we highlight the challenges of using them to conceptualize and operationalize psychological contracts in China and beyond.
\end{abstract}

\section{Keywords:}

Psychological contract; China; qualitative, promise, obligation. 


\section{Same Words, Different Worlds: Exploring Differences in Researcher and Participant Understandings of Promise and Obligation in the Psychological contract}

The psychological contract is at the heart of the employment relationship (Robinson \& Morrison, 2000; Low \& Bordia, 2011) and its unique contribution to our understanding lies in its focus on an employee's subjective employment experiences (Rousseau, 1989; 1995; 2011). Individual contractual beliefs form a fundamental element of the psychological contract (Conway \& Briner, 2005), and whereas earlier psychological contract research tended to study employment expectations, the contemporary literature emphasizes two main concepts of promise and obligation (Bankins, 2014; Rousseau, 2011). Although used in the literature as theoretical concepts, promise and obligation are also words used in everyday language. Ordinary words can be used and interpreted rather differently between the realms of scholarship and everyday language (Boholm, Moller \& Hansson, 2016), so it is important to explore local meanings of theoretical concepts (Bartunek \& Seo, 2002) in this instance to understand whether employees interpret the words promise and obligation in the same way as researchers. The clarity of the meanings of promise and obligation are thus not merely definitional or conceptual matters (Conway \& Briner, 2009; Rousseau, 2011) but also empirical questions. This study was inspired by the research evidence suggesting that promise and obligation are both conceptually different (see Conway \& Briner, 2005; Rousseau, 2011) and empirically distinguishable (e.g., Cassar \& Briner, 2009; Roehling, 2008) from each other. Accordingly, the primary aim of this study is to systematically compare the meanings of promise and obligation from participants' perspectives, with an intention to then compare researcher and participant understandings of these two concepts. This is especially important because previous research has suggested that the existing theory lacks adequate theoretical clarity to appropriately inform deductive studies (Ma, 2016) and there are urgent needs for further theoretical developments, especially in the 
area of promise and obligation (Bankins, 2010; 2014).

Sensitivity to differences in how individuals might understand elements of the psychological contract has been highlighted previously. Rousseau (2000) expressed caution about the extent to which a concept developed in the individualistic, free market, hire at will context of the USA might translate to other contexts, and Rousseau \& Schalk (2000) highlighted the potential influence of different cultures, labor markets and legal systems. In exploring whether participants might view obligation and promise differently from researchers, it therefore makes sense to gather data in a different location, away from the widely studied Anglo-American culture, as Briner \& Cassar (2009) did by gathering data on the nature of the psychological contract in Malta. For our study we chose to examine the issues in a Chinese context, interviewing 61 participants from diverse occupational backgrounds. China has attracted more and more attention from management scholars, and is now the most studied non-Western context for psychological contract research (Hornung \& Rousseau, 2012). Thus, it is important to examine how Chinese workers interpret promise and obligation in their own employment contexts, in order to compare promise and obligation from the employees' perspectives. As the first study to focus systematically on the local conceptualizations of promise and obligation in China, this paper also provides new insights on the extent of cultural transferability of the concepts. Our findings extend the existing literature by identifying three criteria on which promise and obligation may be perceived to differ. Our findings show remarkable similarities with that of Cassar and Briner (2009), but also indicate clear discrepancies between researcher and participant understandings of the two concepts. We suggest such discrepancies deserve further inquiry, especially in light of ongoing calls for theory which is relevant to practice (e.g., Van De Ven \& Johnson, 2006; Kieser \& Leiner, 2009) and the advice that a congruence between researcher and participant understandings of concepts is prerequisite to the practical relevance of research (Bartunek \& 
Seo, 2002). Finally, we suggest that promise and obligation can be interpreted sufficiently differently from one another, and between researchers and participants, to warrant further research into their different functions in employment relationships and psychological contracts, especially in a given cultural context.

\section{LITERATURE REVIEW}

\section{Comparing promise and obligation}

Despite the pivotal positions of promise and obligation in psychological contract theory and research (Rousseau, 1989; 1990; 1995; 2001; 2011), our understanding of these concepts is confined to their conceptual meanings and theory-based assumptions (Conway \& Briner, 2005; 2009; Rousseau, 2011). While Rousseau (2011) underscored that promise and obligation are two different concepts, and scholars have suggested several conceptual differences between them (Conway \& Briner, 2005; Morrison \& Robinson, 1997; Rousseau, 2011), these differences require further elaboration and clarification (Conway \& Briner, 2005; 2009). Little empirical work on the psychological contract has systematically compared the two concepts (for exceptions see Cassar \& Briner, 2009; Roehling, 2008), hindering the development of greater conceptual clarity and precision (Anderson \& Schalk, 1998; Roehling, 2008) and integration of the existing literature (Conway \& Briner, 2005). The concept of promise in the psychological contract emerged from the legal literature on promissory contracts (Rousseau, 1989). Promise is defined as 'a commitment to do (or not do) something' (Rousseau \& McLean Parks, 1993: 6), 'a spoken or written assurance made to another, a commitment made to one’s self, or conditions that create expectations on the part of another' (Rousseau, 2001: 525). Scholars have also defined promise as 'an assurance that one will or will not undertake' (Conway \& Briner, 2005: 23) and a 'declaration assuring that one will or will not do something' (Roehling, 2008: 
263). Other definitions of promise can be found in fields such as philosophy and law (for a recent review see Bankins, 2014). Rousseau (1995) highlighted the importance of the idea of 'reliance losses' in understanding promise within the psychological contract, meaning only a broken promise causing 'behavioral losses’ counts as a psychological contract breach. Overall, the theoretical foundation of promise in psychological contract literature seemed to follow Searle's (1969) speech act theory which helped to distinguish implicit and explicit promises (see Rousseau, 1995; 2001; Bankins, 2010; 2014), while the more recent emphasis appears to fall on the normative feature of promises (Rousseau, 2011).

The concept of obligation has its origin in social exchange theories (e.g., Blau, 1964), and was formally introduced into the psychological contract by Rousseau (1990: 393) to assess psychological contracts, because "obligations bind an actor 'by promise or contract' to a course of action”. Similar to promise, obligation is 'a commitment to some future action' (Rousseau, 1995: 6), defined as 'actions to which the individual or employer is bound' (Rousseau, 2011: 209). Other definitions noted by psychological contract scholars referenced different dictionaries (Conway \& Briner, 2005; Roehling, 2008). For example Roehling (2008: 263) cites a definition of obligation as 'a duty, contract, promise, or other social, moral, or legal requirement that compels one to follow or avoid a certain course of action'. The existing psychological contract literature provides two main conceptual perspectives to understand obligations. Shore and Barksdale (1998), following Blau (1964), emphasize that feelings of obligations arise when people are recipients of beneficence, maintaining a social exchange relationship based on a history of beneficial actions in the long-run. While from a cognitive perspective, Rousseau (2001) explains that psychological contracts take the form of exchange obligations based on individual schemas developed over time. 
We can see that, notwithstanding their different theoretical and philosophical roots, promise and obligation have been defined somewhat similarly in the psychological contract literature, with a common emphasis on the feeling of commitment toward a certain course of action. Psychological contract scholars have however suggested several criteria to compare the two concepts. First, promise and obligation arise from different sources. Whereas the relevance of research on promise to forming psychological contracts lies in promises conveyed in words and through actions (Rousseau, 2001), perceived obligations may come from multiple sources such as social norms, the law and moral duties (Roehling, 2008) ${ }^{1}$. Second, promise and obligation may serve different functions in a given relationship. Obligations have been long recognized as maintaining social norms and long-term relationships (e.g., Gouldner, 1960; Blau, 1964). While promises also serve important functions in maintaining relationships (Rousseau, 1995), they 'create not only obligations but also trust by providing information that people would not otherwise possess about another's intention’ (Rousseau, 2001: 526). Making promises seems to offer assurances and/or evidence of future intentions (Rousseau, 2001). The final distinction between promise and obligation is the motivation for fulfillment. While both promises and obligations are prone to social pressures to fulfill, their motivational foci appear to differ. Psychological contract research tends to theorize obligation as fulfilling patterns based on reciprocity (Gouldner, 1960) and social exchange (Blau, 1964), using terms such as 'reciprocal obligations’ and 'exchange obligations’ (e.g. Rousseau, 1990; 1995; Shore \& Barksdale, 1998; Morrison \& Robinson, 1997). In contrast promises are conceptualized as self-regulating (see Rousseau, 1995: 24-26), creating trust-based and behaviorally reliant employment relationships (Rousseau, 1995; 2001; Morrison \& Robinson, 1997). It is noteworthy that promise

\footnotetext{
${ }^{1}$ Morrison and Robinson (1997) argued that only promissory obligations would fall within the scope of psychological contracts, while more recent research seems to support the argument that perceived obligations may be formed through other sources (Conway \& Briner, 2009; Roehling, 2008; Rousseau, 2001; 2011).
} 
and obligation have been argued to have different probabilities to materialize and (thus) generate different levels of psychological engagement, although researchers tend to have different views on this matter (see Conway \& Briner, 2005; Roehling, 2008; Rousseau, 1989, 2011). We further elaborate these differences in the next section, examining empirical studies that have examined both promises and obligations.

\section{Empirical Comparisons of Promises and Obligations}

Many scholars have called for greater attention on the definitional and construct clarity issues of the psychological contract (e.g., Anderson and Schalk 1998; Guest, 1998; Conway \& Briner, 2009), but very little empirical work has compared the alternative psychological contract conceptualizations and operationalizations. We identified only two studies which have examined if and how the theoretically identified distinctions between promise and obligation may be manifested in research findings.

Roehling (2008) examined to what extent promises, obligations and expectations were quantitatively equivalent. Taking an existing psychological contract survey he developed two further methodologically equivalent surveys, one focused on assessing employee expectations, the other on assessing employee beliefs about employer and employee promises. A sample of 1054 employees from a range of organizations were randomly given one of the three versions of the survey, and their responses were analyzed taking into account six contextual factors (education, organizational tenure, age, equity sensitivity, work centrality and trust). The results indicated the alternative conceptualizations were not fully interchangeable, however they did confirm that promises and obligations share common schematic frameworks (Rousseau, 2001), leading Roehling to conclude that the three alternative operationalizations met 'at least the minimum threshold requirement for meaningful measurement equivalence' (2008:284). 
Roehling’s (2008) findings did not explain the qualitative differences between promise and obligation, and these differences were investigated by Cassar and Briner (2009). Using semistructured interviews, they found participants perceived obligations and promises as different concepts in the employment context, confirming that obligations and promises are qualitatively distinctive. Obligations were perceived to convey an exchange or reciprocal relationship between the employee and employer. Promises, on the other hand, were more uncertain and less binding and made without necessarily expecting anything in return (Cassar \& Briner, 2009). Participants appeared to be more psychologically engaged with the concept of obligations, viewing them as a better predictor of future behaviors and foreseeable commitments (Cassar \& Briner, 2009).

Overall then there is both theoretical and empirical evidence which warrants further studies to better understand promise and obligation, especially in a comparative sense. In reviewing the literature, we observe paradoxical attitudes towards promise and obligation. On the one hand, there is a consensus about the problems of clarity in defining promise and obligation, yet when it comes to empirical research there is an implicit assumption that participants' understanding of the terms would be unproblematic, with no confusion or incongruence among themselves or with researchers. This therefore highlights a neglect of the significance of participants' interpretations of some keywords used in the questionnaires. We suggest this neglect may offer one explanation for Conway and Briner's (2009) observation that, taken as a whole, the empirical findings of psychological contract research are disappointingly inconclusive, and the theory lacks practical application. We address these issues by investigating how obligation and promise vary from each other in the employment context in China, focusing on what workers understand by the two terms, and how they distinguish one from the other. 


\section{METHODS}

This study adopted a non-probability sampling strategy and used semi-structured interviews to collect data, in line with previous qualitative studies in the field (Cassar \& Briner, 2009; Nadin \& Cassell, 2007; O’Leary-Kelly, Henderson, Anand \& Ashforth, 2014; Tietze \& Nadin, 2011). We used variety maximization sampling in order to minimize effects/findings specific to a given context. As a result, our participants were drawn from significantly diverse personal, employment and professional backgrounds from various industries in both private and government sectors. In total, 61 participants were recruited through the personal networks of the first author, supplemented by a snowball sampling approach to maximise sampling variety. Because we were interested in participants' interpretations of 'promise' and 'obligation', from their perspectives and in their own words, we did not provide them with any definition of these concepts. At the start of the interviews we simply stated we were interested in exploring their experience of work life and their personal understanding of the meanings of some ordinary Chinese words as they would apply in their employment settings.

Since our primary interest lies in individual interpretations, a 'free list' approach was used to uncover the local meanings (Bartunek \& Seo, 2002: 240), which involves the interviewer allowing the interviewee to freely associate any words, explanations, concepts, and/or incidents when relating their understandings of a given concept/word, while the interviewer tires not to provide any guideline or framework for interpretation. This approach is particularly appropriate for research aiming to explore how scholarly concepts are interpreted or manifested in a given context (Bartunek \& Seo, 2002) and therefore adopted for this study. The main interview protocol included direct questions to ask: (1) what the participants understood by promise and 
obligation in the employment context ${ }^{2}$; (2) whether they perceived any difference between the two terms and if so how/what; and (3) examples of each concept in their own work settings. In accordance with a free list approach, no definition or explanation of promise and obligation was given to the participants during the interviews; they were asked to give personal understandings based on their individual interpretations of the words. All interviews were conducted in Mandarin by the first author and subsequently transcribed. Each transcript was annotated with an English pseudonym for the participant to ensure confidentiality. We used template analysis as a way of clustering the meanings of participants (King, 2004). We read all transcripts to code the most saliently revealed interpretations by extracting participants' direct meanings ascribed to the respective concepts, which were subsequently refined by coding the available employment examples. We coded across transcripts for template revision and read within transcripts for template validation.

\section{FINDINGS}

The final template includes three main themes (first-order codes) around which the findings were structured (see Table 1), representing the clearly identifiable issues in the transcripts regarding the comparison of promise and obligation.

Insert Table 1 about here

\section{The Defining Characteristics of Promise and Obligation}

Our data suggests that promise and obligation each had a defining characteristic that made the two concepts distinguishable from each other for participants. The participants tended to speak

\footnotetext{
2. Based on the PCI used by Hui, et al. (2004), the translations of 'promise' and 'obligation' used were 'chengnuo' (' $\square$ ( ') and 'yiwu' (' $\square$ '), respectively.
} 
about such characteristics very readily, often as their first response, so the defining characteristics of promise and obligation were identified in the vast majority of the transcripts, with consensus among the participants.

For promise, there is considerable consistency among the participants in relating the concept to something they had agreed to do:

I think promises are things you must do because you have agreed to do it. (Aaron)

By contrast obligation is predominantly associated with duties related to the participants' work, professions, jobs and/or positions:

Simply put, obligations are what should be done by whoever is in the job position. (Penelope)

Our findings suggest agreement is pivotal to promise's self-regulating mechanisms (Rousseau, 2001), while the sense of duty renders obligation generally more binding than promise (Rousseau, 2011). These distinct defining characteristics of promise and obligation work as an analytical lens, through which the commitment features and employment manifestations of the concept can be understood. Though both promise and obligation elicit commitments, they differ in terms of the commitment attribution and the source and strength of the binding powers, and it is to this analysis we now turn.

\section{Key Commitment Features of Promise and Obligation}

Our data showed that promise is attributable to the promisor (Roehling, 2008). Participants 
ascribed promises to the conscious decision made by the person agreeing to the commitment, holding the promisor personally responsible for keeping and breaking a promise:

If you agreed on something...but did not do it well, that's your fault. You should have told me that you couldn't do it; you should have been clear as to what extent you could do it... This is promise. (Lisa)

This attribution to the promisor can be understood from two perspectives. First, the agreement defining promise resides with the person making the promise. This gives rise to the most salient feature of promise-making, its discretionary nature. Making a promise indicates an autonomous choice:

Promise means that you may choose to promise or not, depending on whether you are willing to do what is promised. (Angela)

Promises are mutual agreements which I think involve a communication process in advance...You have a choice whether you want to promise or not. (Brian)

Accordingly, this discretionary nature of promise denotes that promise-making is usually also discretional, meaning that promise implies some power to act on its delivery and is expected not to be made in an unconsidered manner. The data analysis shows a promise decision is strongly associated with the likelihood of promise-keeping, commonly weighed against the participants’ own limits of delivering the promise:

I think promise means having to deliver what's agreed to do. If you can't then don't make promises to anyone... I think if I promise something I will just have to do it. I feel 
that if I can agree to do what is promised, I can do it. If I feel I can't do it, I just won't agree to do it. (Rebecca)

In other words, promise implies the promisor's choice to enter, and willingness and capability to honor, the agreement. Because the commitment is attributable to the promisor, the source of binding power seems to come largely from within. The data indicates clear action orientations toward the promised commitments by the promisor, i.e., 'make it happen' or 'do it'. When asked why they thought that promises should be kept, many participants appealed to the internalized binding power of promises:

Feels like I have promised you this thing, so I just have to make it happen. (Linda)

Promise is like you have promised, you've just got to do it. This is my personal understanding. (Anna)

While the exact nature of this internal binding power is hard to determine, our analysis suggests morality is a major factor. Promise elicits a sense of moral obligation, committing the promisor toward acting upon the promise:

Promise is something that you must do because you have obligated yourself by the willingness to promise. If you are unwilling to do something, then don't agree to it; but once promised, just do it. (Victoria)

Promises are considered from the moral angle. (William) 
Promise has moral binding powers. (Elaine)

Promise thus appears to be morally self-sufficient for commitments, generating an internalized motivation for promise-keeping. However, the binding power of such internalized morality of promise appears to be uncertain, despite promoting a propensity toward promise-keeping (see above). In reality the level of binding power and reliability of a promise relates to issues which are more subjective and personal in nature. This is likely because morality is less enforceable (compared to obligations, see below) and thus its binding power is individually varied and more contextual. Consistent with this, our data show that promise's binding powers are strongly associated with the qualities of the person making the promise e.g. trustworthiness, morality and credibility:

It ('promise') has binding powers if the person (making it) has some sense of responsibility - it depends on the person. (Jason)

Promise is absolutely related to trust and credibility...talking about promise, this is the most basic quality (of the person making the promise). (James)

Promises are perhaps a kind of more abstract commitment, relating more to your personal quality, sort of morality’. (Sara)

Whereas promise was attributed to the individual, our participants attributed obligations to multiple sources, associated with varied motivations and generally stronger in binding powers. The primary source of obligation identified by our participants is the legal contract. The majority of our participants readily associated obligations with in-role duties: 
Obligations are perhaps the kind of objective thing...written in the contract and company regulations. (Elena)

As contractual relationships usually define the duties of both parties, obligations were perceived to have a bidirectional nature. Specifically, our participants referred this to their perceptions that obligations are corresponding to rights. Elena captured this neatly:

Obligation, I think, is just a value relationship between two parties and a relationship of mutual interests...For example, what values I contribute to and then what entitlements I gain from the company...To me, obligations are just corresponding to rights.

While most participants associated obligations in line with the above two themes, we also identified two types of less frequently mentioned norm-based obligations in the data. Professional norms based obligations were especially ascribed to by teaching and nursing professionals in our sample, who often regarded their profession-based extra-role commitments as part of the job. They also often, but not always, exhibited strong and taken-for-granted commitments toward the corresponding obligations:

Things you do naturally...As a teacher, educating students well is within the own work. Striving for every student's improvements and even solving problems encountered in teaching - these all should be obligations, i.e., things within the work scope. (Paul)

While also seemed taken-for-granted, the social norms based obligations were more implied than directly mentioned in the participants' accounts of helping behaviors, mostly toward 
friends and family members:

Meaning of obligation? You see, for example, mothers must take good care of their children; they naturally want the best for them. (Rachel)

If there is a need, if other colleagues need me, I will try to help (Linda).

\section{Manifestation of Promise and Obligation in the Employment Setting}

In general, our analyses show that promises tend to be oral, informal and thus unspecific in the employment context, whereas obligations are probably written, formal and thus easier to identify. Accordingly, promises tend to be more flexible, whereas obligations tend to be more concrete at work. As a result, employment promises tend to cover commitments beyond the job description which are less specific and harder to articulate:

There is no way to describe detailed promises, because they vary according to different periods of work...although according to our thoughts, promises relate to those things beyond the company required duties. (Caroline)

In contrast, obligations were related to the formal role of obligations in employment and thus more readily identifiable to the participants, but evidently narrower in scope. Frequently, the participants interpreted employment obligations as duties specified in the contract or job description:

More detailed obligations are just what's written in the contract when you entered the company - that's your obligation. It is not your obligation if it is not written. (William) 
The sharp contrast was particularly revealed when the participants were asked to compare the two concepts:

Obligations are a kind of mutual duties and responsibilities based on the signed contract...Promises are not written on the paper so that you can't take it to a formal level. (Jeremy)

Obligations, for example, it's like I am on this position so I should do these things...Promise is something of my personal wishes...,definitely not in the contract because they refer to things that are less concrete, unspecific or even abstract, depending on personal relationships and intentionality. (Nicolas)

Obligations are the things you and your employer must certainly do in the employment relationship....Promises are uncertain because they are oral...It means that they are not that formal or binding...They may be conditional and cancelled later. (Sally)

It is important to note that, while a variety of sources were drawn on to interpret obligations in employment context, the vast majority of the participants drew upon legal responsibilities when asked to relate the concept to their own work. The data suggest obligations were primarily associated with contractual exchanges closely related to the job, whereas promises were mostly reflected in individually varied and internally motivated work arrangements ascribed to contextually framed mutual agreements. To offer a clearer and more holistic view, we provide one participant’s particularly articulate comments comparing promise and obligation: 
You may or may not fulfil a promise; it all depends on the individual...Promises are verbal, meaning there is no legal binding power and thus no consequences for inaction on it...It is only a matter of personal credibility...or a promise relationship that depends on the trust toward each other in the mutual relationship... 'Obligation', as a noun, I think it is based on the law... Obligations may involve legal relationships, noncompliance of which may lead to certain consequences... Obligations usually involve documentation... the obligations between our company and us...are because we signed the contracts. (Matt)

\section{DISCUSSION \& CONCLUSION}

Our findings suggest promise and obligation are distinguishable in the Chinese context both at the conceptual level and in terms of their manifestation in the employment relationship. The data shows the participants view promises as eliciting commitments attributable to the promisor, which are based on the promisor's conscious and willing agreement regarding the promise. Accordingly, the motivation toward a promise is largely internal in nature, and a promise's binding powers largely stem from morality and tend to be contextual. In contrast, while they view obligations as arising from a variety of norm/rule-based sources corresponding with varied motivations, binding powers and commitments, they primarily associated obligations with laws and contractual exchanges. Thus, obligations are perceived to form the very foundation of formal employment relationships reflecting commitments which are stronger but narrower in scope; whereas promises appear to arise from more nuanced interactions eliciting internally motivated, but individually varied responses. The commitment features of promise in the Chinese context seem largely in accordance with Rousseau's $(1995,2001)$ notion of promise, in- 
dicating considerable empirical support for the assumed utilities of promise in the psychological contract. She reasons that communication and freedom to choose are critical prerequisites for promise, which motivationally engender a personal commitment to carry out a promise (Rousseau, 1995). This was supported by the Chinese workers' perceived volition in promise behaviors. To varying degrees, the features of promise in employment such as flexibility, uncertainty, moral binding powers, individuality and sensitivity to contexts (Bankins, 2014; Cassar \& Briner, 2009; Rousseau, 1995, 2001, 2011) were also supported. Similarly, our findings are consistent with the premise that obligations form the basic building blocks of employment relationships and thus tend to be more binding than promise (Cassar \& Briner, 2009; Rousseau, 2011). These results indicate that the fundamental assumptions about promise and obligation that underpin psychological contract theory and research are applicable in Chinese societies, especially considering the diverse participants' backgrounds. However, while both concepts are generally applicable in China, there may nevertheless be challenges involved in using promise and obligation to study Chinese psychological contracts.

Our data indicates that participants found it relatively easy to illustrate how obligation is manifested in the employment relationship, but the examples offered were almost always related directly to contractual duties, and as such were concerned with the employment contract rather than the psychological contract. By contrast their descriptions of promise, emphasizing agreements and related concepts such a volition, choice, communication and self-regulated mechanisms (Rousseau, 1989, 1995), went clearly to the heart of the psychological contract. However, when pressed for illustrative examples our participants appeared to find it harder to identify promises in the employment context, especially on the employer side. It appears that Chinese workers have an understanding of promise and obligation similar to Western workers. Yet 
we might still struggle to operationalize these definitions in ways meaningful for Chinese employment relationships. How might we explain this? We suggest two possible explanations, both of which may be correct. The first relates to the context of Chinese employment relationships. The origin of the psychological contract metaphor is the notion that the employment relationship involves an unwritten 'deal' between employer and employee, over and above the legal employment contract. It is possible most Chinese employees do not experience the employment relationship in these terms, but instead as a 'take it or leave it' offer from the employer, in which the emphasis is on what the employee might be expected to do for the employer (Rousseau, 1995). The second possible explanation relates to the subtle differences between English and Mandarin forms of the terms promise and obligation. While promise has several usages in the English language (Rousseau, 2011), its Chinese equivalent ('chengnuo’3) is univocal, meaning to commit to an agreed course of action, i.e., to 'act according to what is agreed to do' (Xinhua Chinese Dictionary, 2013:125). The simpler, narrower definition of promise in Chinese appears to have determined the understanding of the participants, who consistently defined the concept with reference to agreements made by the individual in a given context. As a result, a promise-based psychological contract would be harder to ascertain for Chinese workers (and too individualistic to measure quantitatively), whereas an obligationbased psychological contract would be linguistically biased toward a more normative and thus restrictive scope of work commitments in the Chinese language.

While a seemingly good compromise has been to use both promises and obligations to assess Chinese psychological contracts (e.g., Gardner, Huang, Niu, Pierce \& Lee, 2014; Hui, Lee \& Rousseau, 2004; Shih \& Chen; 2011), this can still be problematic. Since obligations tend to be primarily associated with in-role duties and (employer) promises may be less common

\footnotetext{
${ }^{3}$ Coincidentally the English word 'commitment' may also be translated as 'chengnuo' in the Chinese language.
} 
and/or obvious in the Chinese employment context, psychological contract measures using either/both of these terms could be culturally and linguistically inducing responses biased toward obligations rather than promises, and thus towards the transactional end of the psychological contracts continuum (Rousseau, 1995; Hui et al., 2004; Zhao \& Chen, 2008). This provides an alternative explanation as to why previous studies consistently find Chinese workers' psychological contracts to be transactional in nature, even though theory would lead us to expect them to be more relational (see Hornung \& Rousseau, 2012). The bias introduced by these linguistic differences might be less likely to occur in qualitative studies, as both researcher and participant usually have the chance to explore and clarify any ambiguity in the meaning of terms used. This is supported by the results of the qualitative study undertaken by Thomas, Fitzsimmons, Ravlin, Au, Ekelund \& Barzantny (2010), whose results highlighted a relational nature to employment exchanges in China, consistent with its collectivist culture.

Consistent with suggestions that Chinese workers may interpret psychological contract measures differently than their western counterparts (Hornung \& Rousseau, 2012), and existing empirical evidence implying a need to contextualize psychological contract measures in China (e.g., Lee, Liu, Rousseau, Hui \& Chen, 2011), this study provides further direct empirical evidence in calling for further research to investigate these issues in the Chinese context. Linguistically, a potentially useful Chinese word to consider as an alternative term is 'responsibility' ( u , or 'zeren'), which has been used to operationalize several contextualized psychological contract measures in Chinese by a large number of Chinese psychological studies. It is premature to make further recommendations without more robust definitions of promise and obligation, but we suggest scholars be mindful of the issues discussed here in their interpretations of results from studies using promises and/or obligations, especially the translated versions of the established western measures to assess psychological contracts in China. 
Taking our discussion beyond China, we compare our findings with the Western/other participants' meanings of promise and obligation by focusing on Cassar and Briner (2009), which was the only empirical study found to explicitly explore the local meanings of the concepts. Similar to our study but in Malta, Cassar and Briner (2009) conducted a study with semi-structured interviews that in parts explores their participants' interpretations of and comparisons between promise and obligation. The comparison between ours and their results yield striking similarities. Both sets of data suggest both the meanings and concepts of obligation are primarily and predominantly embedded in the framework of employment contract, including in the Maltese context the binding, mutual, and/or contractual exchange agreements. Almost identical to our results, Cassar and Briner (2009: 684) conclude that '(a)ll the participants defined "employment obligations” primarily as constituting contractual terms in an employment relationship'. Thus, in both contexts, obligations are perceived to be concrete, written and anchoring employment relationships, eliciting strong and binding commitments. Although this is in line with the emphasized binding power of obligation by scholars, the empirical scope of employment obligations perceived by the participants across English and non-English linguistic contexts (i.e., employment contracts) appears to be significantly narrower than that construed by scholars. Furthermore, many defining conceptual features of obligation in scholarship, for example, obligation's binding power through promise (Rousseau, 1990) or multiple sources of obligation (Roehling, 2008), are at best marginally reflected by the participants’ meanings. Similarly, the participants from both studies view promises primarily as personal undertakings and thus in general less binding, harder to pinpoint, while promise-keeping is an unenforceable and an individually varied behavior. For example, 'anyone can promise anything and there is nothing that binds a promise....in my position, at the moment, there are no promises...the only thing is that I have to work' (participant 8, in Cassar \& Briner, 2009: 685). This is in sharp 
contrast with promise's definitions which explicitly define the concept by assurance (e.g., Rousseau, 2001; Conway \& Briner, 2005; Roehling, 2008), and marginally supportive to the most profound conceptual discussions on promise which explain how it ought to elicit commitments (e.g., Rousseau, 1995; 2001; Conway \& Briner 2005; Bankins, 2014). Given these discrepancies in understanding between researchers and participants, we appeal for more rigorous definitions of promise and obligation which are critical for the empirical research of a quantitative nature. This is because an imprecise definition of a key word used to operationalize a concept can be very problematic (Bartunek \& Seo, 2002), especially when that key word has multiple lexical meanings and frequent usages in the everyday language (e.g., Boholm, Moller \& Hansson, 2016) as in both cases of promise and obligation, and even more so when there are significant issues of translation from one language to another (Blenkinsopp \& Shademan-Pajouh, 2010). Our analyses suggest this caveat is particularly pertinent to psychological contract research.

In light of the empirical evidence from the present study, and that of Cassar and Briner (2009), both of which suggest significant differences between promise and obligation by the participants, we further appeal for rigorous theoretical and empirical research on promise and obligation which treats them as independent concepts. In line with the conceptual discussions suggesting that promise and obligation imply different levels of psychological engagement (e.g., see Conway \& Briner, 2005; Roehling, 2008; Bankins, 2014), our analysis further suggests promise and obligation may have different functions and relevance in employment relationship, especially in China. Since obligations are more duty oriented, tend to be strongly binding (Rousseau, 2011) and serve as the building blocks of employment relationship (Cassar \& Briner, 2009), it may be that employment obligations anchor the formal employment relationship by providing stable mental frameworks guiding our everyday understanding of what 
should be taken for granted (see Conway \& Briner, 2005). Similarly, obligations could be more relevant during uncertainty where the parties to a relationship might prefer a sense of stability. On the other hand, promises are trust-based (Robinson, 1996) and self-regulated commitments (Rousseau, 1995), which provide extra information regarding the other party's intentions (Rousseau, 2001) and tend to be more flexible in employment manifestations and conceptually versatile (Rousseau, 1998). Accordingly, promise behaviors are more likely to encourage changes and to prevail in high-trust (and equal power) relationships and innovative environments. Related to this, future research may consider the possibility that obligation and promise may be more relevant to particular types of psychological contracts, i.e., transactional and relational contracts respectively (Rousseau, 1995), especially in cross cultural studies. For example, whilst obligation in both Chinese and Maltese contexts would seem to be largely in line with transactional contracts (which emphasize short-term, equal value economic exchanges in employment with a narrower scope of reciprocal commitments), promise in China would appear appropriate for relational contracts emphasizing trust, relationship and social exchange with individualized commitments which are sensitive to context and broader in scope. Our findings and analyses suggest promise and obligation are interpreted differently by the participants and have different manifestations in employment, which led us to put forward a bold suggestion that we stop focusing on the entangling issues of whether to use promise or obligation to operationalize (Rousseau, 2011) and theorize (Bankins, 2014) psychological contracts, or whether they are interchangeable (Roehling, 2008; Conway \& Briner, 20005). Instead, we might want to ask which would be the most appropriate concept to construe or key word to measure what kind of psychological contracts, in which cultural context.

Finally, our findings suggest that features of psychological contracts may vary according to national contexts (Cassar \& Briner, 2009; Rousseau \& Schalk, 2000). For example, Cassar and 
Briner (2009) concluded a homogenous and primary source of employment obligations, i.e., the contractual relationship at work; while we found a minority of our participants mentioned other norm based obligations such as voluntarily helping a patient, student or colleague without an expectation of any return. On promise, Cassar and Briner's (2009: 685) participants perceive promises as 'less likely to be of any importance in an exchange relationship', while our data suggests that promise in China clearly carries a strong moral implication which may give rise to internalized but individually and contextually varied binding powers in the Chinese culture. Because reasoning about moral obligations may differ in different cultural contexts (e.g., Keller, Edelstein, Krettenauer, Fang \& Fang, 2005), future research may look into how moral promise behaviors vary, and thus influence psychological contracts accordingly, across cultural contexts. In the Chinese context in particular, we concur with Hornung and Rousseau (2012) in calling for more qualitative research on psychological contracts, especially with regard to Chinese workers' own accounts of their employment experiences. On a last practical note, one caution especially for expatriate managers in China is to avoid using (explicit) promises to signify future intentions, as they might do in a Western context. Our findings suggest a tendency for the Chinese employees to perceive promises as concrete agreements and, if such agreements are unfulfilled the Chinese employees may be more likely to attribute promisebreaking to internal factors, resulting in the personal credibility and qualities/characters of promise-making managers being seriously questioned.

In addressing the research aim of this study, we found promise and obligation varied from each other in terms of the defining characteristics of the concept, key commitment features and manifestation in employment in China. They also differ in the attributions, sources of motivations and binding power, albeit in less clear-cut ways. While our findings provide qualitative evidence that the conceptual fundamentals of psychological contracts are generally applicable in 
the Chinese context, we also identify several challenges associated with both concepts in studying psychological contracts in China and beyond. Promise and obligation are likely to be sufficiently distinctive in many cultures to warrant further investigations into them as separate entities potentially pertinent to different and respective psychological contracts in a given cultural context. Furthermore, there are marked discrepancies between researcher and participant understandings of the two concepts, and researchers should therefore guard against using these concepts unreflectively in future psychological contract research.

\section{REFERENCES}

Anderson, N. \& Schalk, R. (1998). The psychological contract in retrospect and prospect. Journal of Organizational Behavior, 19: 637-647.

Arnold, J. (1996). The psychological contract: a concept in need of closer scrutiny? European Journal of Work and Organizational Psychology, 5(4): 511-520.

Bankins, S. (2010). Expectations, obligations or promises? A conceptual review and revision of the beliefs comprising the psychological contract. 24th Annual Australian and New Zealand Academy of Management Conference: Managing for Unknowable Futures, 810 December, 2010, Adelaide.

Bankins, S. (2014). Delving into promises: Conceptually exploring the beliefs constituting the contemporary psychological contract. Journal of Management \& Organization, 20(4): 544-566.

Bartunek, J.M. \& Seo, M.G., (2002). Qualitative research can add new meanings to quantitative research. Journal of Organizational Behavior, 23(2): 237-242.

Blau, P. M. (1964). Justice in social exchange. Sociological Inquiry, 34(2): 193-206.

Blenkinsopp, J. \& Shademan Pajouh, M. (2010). Lost in translation? Culture, language and the role of the translator in international business. critical perspectives on international business, 6(1), 38-52.

Boholm, M., Möller, N. \& Hansson, S.O. (2015). The Concepts of Risk, Safety, and Security: Applications in Everyday Language. Risk Analysis, 36(2): 320-338.

Cassar, V. \& Briner, R. (2009). Contextualizing the features of the psychological contract: the case of Malta. Journal of Managerial Psychology, 24(7): 677-694.

Chaudhry, A., Wayne, S. J. \& Schalk, R. (2009). A sensemaking model of employee evaluation of psychological contract fulfillment when and how do employees respond to change?. The Journal of Applied Behavioral Science, 45(4): 498-520.

Conway, N. \& Briner, R. B. (2005). Understanding psychological contracts at work: A critical evaluation of theory and research. Oxford: Oxford University Press.

Conway, N. \& Briner, R. B. (2009). Fifty years of psychological contract research: What do we know and what are the main challenges. International Review of Industrial and Organizational Psychology: 71-131.

De Vos, A. \& Freese, C. (2011). Sensemaking during organizational entry: Changes in newcomer information seeking and the relationship with psychological contract fulfilment. Journal of Occupational and Organizational Psychology, 84(2): 288-314. 
Dick, P., \& Nadin, S. (2011). Exploiting the exploited: The psychological contract, workplace domination and symbolic violence. Culture and Organization, 17(4): 293-311.

Gardner, D. G., Huang, G. H., Niu, X., Pierce, J. L. \& Lee, C. (2014). Organization-based selfesteem, psychological contract fulfillment, and perceived employment opportunities: A test of self-regulatory theory. Human Resource Management, 54(6): 933-953.

Gouldner, A. (1960). The normal of reciprocity: A preliminary statement. American Sociological Review, 25(2): 161-178.

Guest, D. E. (1998). Is the psychological contract worth taking seriously? Journal of Organizational Behavior, 19(S1): 649-664.

Herriot, P., Manning, W. and Kidd, J. M. (1997). The content of the psychological contract. British Journal of Management, 8(2): 151-162.

Hornung, S. \& D. M. Rousseau. (2012). Psychological contracts of Chinese employees. In Huang, X. and Bond, M. (ed.), Handbook of Chinese Organizational Behavior: Integrating Theory, Research and Practice: 326-342 Edward Elgar Publishing.

Keller, M., Edelstein, W. and Kreitenauer, T., Fang, F and Fang, G. (2005). Reasoning About Moral Obligations and Interpersonal Responsibilities in Different. Morality in Context, 137: 317-337.

Kieser, A., \& Leiner, L. (2009). Why the rigour-relevance gap in management research is unbridgeable. Journal of Management Studies, 46(3), 516-533.

King, N. (2004). Template analysis. In: Cassell, C. and Symon, G. (ed.), Essential Guide to Qualitative Methods in Organizational Research. London: SAGE.

Li, Y. \& Yu, J.Y. (2012). Research of Evaluation Staff Psychological Contract Based on BP Neural Network. Journal of Xuzhou Normal University (Philosophy and Social Sciences Edition), 38(1): 212-124.

Low, C. H., \& Bordia, P. (2011). A career stage perspective on employees' preferred psychological contract contributions and inducements. Journal of Management \& Organization, 17(6): 729-746.

Ma, G. (2016). A Qualitative inquiry into Chinese workers' understanding of the key psychological contract concepts of 'obligation', 'promise' and 'other Party'. Unpublished PhD thesis, University of Hull, UK.

Ma, Y.F., Sun, J.M. \& Pan, S.Y. (2010). Analysis of the state of psychological contract in manufacturing enterprises. Soft Science, 24(6): 94-96,105.

Meyer, K. E. (2006). Asian management research needs more self-confidence. Asia Pacific Journal of Management, 23(2): 119-137.

Morrison, E. W. \& Robinson, S. L. (1997). When employees feel betrayed: A model of how psychological contract violation develops. Academy of Management Review, 22(1): 226256.

Nadin, S. \& Cassell, C. (2007). New deal for old? Exploring the psychological contract in a small firm environment. International Small Business Journal, 25(4): 417-443.

O’Leary-Kelly, A.M., Henderson, K.E., Anand, V. \& Ashforth, B.E., (2014). Psychological Contracts in a Nontraditional Industry Exploring the Implications for Psychological Contract Development. Group \& Organization Management, 39(3): 326-360.

Robinson, S. L. (1996). Trust and breach of the psychological contract. Administrative Science Quarterly, 41: 574-599.

Robinson, S. L. \& Morrison, E. W. (2000). The development of psychological contract breach and violation: A longitudinal study. Journal of Organizational Behavior, 21(5): 525546.

Roehling, M. V. (2008). An empirical assessment of alternative conceptualizations of the psychological contract construct: Meaningful differences or "much to do about nothing”?. Employee Responsibilities and Rights Journal, 20(4): 261-290. 
Rousseau, D. M. (1989). Psychological and implied contracts in organizations. Employee Responsibilities and Rights Journal, 2(2): 121-139.

Rousseau, D. M. (1995). Psychological Contracts in Organization: Understanding Written and Unwritten Agreements. CA: SAGE.

Rousseau, D. M. (2000). Psychological contracts in the United States: Diversity, individualism, and accountability in the marketplace. In: Rousseau, D. M., and Schalk, R. (ed.), Psychological Contracts in Employment: Cross-national Perspectives: 251-282. CA: SAGE.

Rousseau, D. M. (2001). Schema, promise and mutuality: The building blocks of the psychological contract. Journal of Occupational and Organizational Psychology, 74(4): 511541.

Rousseau, D. M. (2011). The individual-organization relationship: The psychological contract'.

In: Zedeck, S. (ed.), APA Handbook of Industrial and Organizational Psychology, (Vol 3): Maintaining, Expanding, and Contracting the Organization: 191-220 Washington: American Psychological Association.

Rousseau, D. M., and Schalk, R. (2000). Psychological Contracts in Employment: Cross-national Perspectives. CA: SAGE.

Rousseau, D.M. \& McLean Parks, J. (1993). The contracts of individuals and organizations. In: Cummings, L.L. \& Staw, B.M. (ed.). Research in Organizational Behavior, 15: 143.

Rousseau, D.M., (1990). New hire perceptions of their own and their employer's obligations: A study of psychological contracts. Journal of Organizational Behavior, 11(5): 389400.

Searle, J. R. (1969). Speech Acts. Cambridge: Cambridge University Press.

Sherman, U. P. \& Morley, M. J. (2015). On the Formation of the Psychological Contract A Schema Theory Perspective. Group \& Organization Management, 40(2): 160-192.

Shih, C. T. \& Chen, S. J. (2011). The social dilemma perspective on psychological contract Fulfilment and organizational citizenship behavior. Management and Organization Review, 7(1): 125-151.

Shore, L. M. \& Barksdale, K. (1998). Examining degree of balance and level of obligation in the employment relationship: A social exchange approach. Journal of Organizational Behavior, 19(1): 731-744.

Shore, L. M. (2002). Psychological contracts: Definitions and distinctiveness. Paper presented at the Academy of Management Annual Meeting, Denver.

Suddaby, R. (2010). Editor's comments: Construct clarity in theories of management and organization. The Academy of Management Review, 346-357.

Thompson, J. A. \& Bunderson, J. S. (2003). Violations of principle: Ideological currency in the psychological contract. Academy of Management Review, 28(4): 571-586.

Tietze, S. \& Nadin, S. (2011). The psychological contract and the transition from office-based to home-based work. Human Resource Management Journal, 21(3): 318-334.

Tsui, A. S. (2004). Contributing to global management knowledge: A case for high quality indigenous research. Asia Pacific Journal of Management, 21(4): 491-513.

Van de Ven, A. H., \& Johnson, P. E. (2006). Knowledge for theory and practice. Academy of management review, 31(4), 802-821.

Xinhua Chinese Dictionary ( $2^{\text {nd }}$ ed.) (2013). Business Press International: Beijing.

Yang, K. (2011). Exchange relationships in employment relationships. Productivity Research, 12: 3132,100 .

Zhao, J. \& Chen, L. (2008). Individualism, collectivism, selected personality traits, and psychological contract in employment: A comparative study. Management Research 
News, 31(4): 289-304. 